\title{
Measurement of operating parameters of a hydrogen compressor using metal hydride materials
}

\author{
Tomáš Brestovič ${ }^{1, *}$, Natália Jasminská ${ }^{1}$, Marián Lázár ${ }^{1}$, and Romana Dobáková1 \\ ${ }^{1}$ Faculty of Mechanical Engineering, TU Košice, Department of Power Engineering, Vysokoškolská \\ 4, 04200 Košice, the Slovak Republic
}

\begin{abstract}
The present article deals with the possibilities of using metal hydride materials in the construction of hydrogen compressors. For the purpose of continuous operation, a tandem tank connection is used. By increasing the tank temperature, hydrogen pressure increases as well, whereas the heat is transported between the tanks by means of a heat pump. Operating parameters are measured for the purpose analysing prevention of the device failures that occur when the maximum pressure behind the heat pump compressor is exceeded.
\end{abstract}

\section{Introduction}

Efforts to eliminate the drawbacks of high-pressure and cryogenic method of hydrogen storage lead to the use of metal hydride materials that facilitate hydrogen storage through absorption into the metal structure of the alloy. Hydrogen absorption into the alloy begins once the required pressure is achieved; at such pressure, a catalytic effect of the used metals facilitates dissociation of a hydrogen molecule and subsequent diffusion of hydrogen atoms into the intermetallic space of the lattice $[1,2,3,4]$. The absorption process is accompanied with a slow pressure increase up to the value of complete metal saturation. The plateau pressure, at which the absorption occurs, significantly depends on the alloy temperature $[5,6,7,8]$. The difference in plateau pressures of $\mathrm{MH}$ materials at the acceptable temperature change resulted in the effort to create a hydrogen compressor which would use the heat cycle of MH tank heating and cooling.

\section{Description of the compressor's temperature cycle}

Figure 1 shows the basic temperature cycle of a compressor using the $\mathrm{La}_{0.85} \mathrm{Ce}_{0.15} \mathrm{Ni}_{5}$ alloy that is capable of forming $\mathrm{MH}$. The cycle is drawn in the measured PCI (Pressure Concentration Isotherms) graphs between the temperatures of 10 and $50{ }^{\circ} \mathrm{C}$. The baseline point A represents the initial state of the alloy with the $0.16 \%$ concentration of the absorbed hydrogen at the pressure of $0.12 \mathrm{MPa}$.

\footnotetext{
*Corresponding author: tomas.brestovic@tuke.sk
} 
Hydrogen is absorbed into the alloy between points $\mathrm{A}$ and $\mathrm{B}$ and it is accompanied with the heat release. For the $\mathrm{La}_{0.85} \mathrm{Ce}_{0.15} \mathrm{Ni}_{5}$ alloy, the amount of the released reaction heat is identified by experimental measurements as $1 \mathrm{MJ} \cdot \mathrm{m}^{-3}$ of $\mathrm{H}_{2}$ (measured at $20{ }^{\circ} \mathrm{C}$ ). Following the alloy saturation up to the concentration of $0.66 \%$, the pressure increases up to $0.2 \mathrm{MPa}$. Further concentration increase is inappropriate, with regard to the increasing pressure gradient, as it would lead to the reduction of the compression ratio and to a useless increase of the operating pressure of the compressor (point C). Once the required concentration is reached, the alloy temperature must be increased by adding the heat $[9,10,11,12]$.

$$
Q_{\mathrm{BC}}=\sum_{i}\left(m_{i} \cdot c_{i}\right) \cdot \Delta T+q_{\mathrm{des}} \cdot \Delta V_{\mathrm{des} \mathrm{H}_{2}}
$$

whereas $\Sigma\left(m_{i} \cdot c_{i}\right)$ is the total heat capacity of the MH storage tank, including the integrated heat exchanger and the absorbed hydrogen $\left(\mathrm{J} \cdot \mathrm{K}^{-1}\right), \Delta T$ - the difference between the temperatures of working isotherms $(\mathrm{K}), q_{\mathrm{des}}-$ reaction heat at hydrogen desorption $\left(\mathrm{J} \cdot \mathrm{m}^{-3}\right)$, $\Delta V_{\text {des H2 }}$ - amount of released hydrogen at the temperature increase in $\Delta T\left(\mathrm{~m}^{3}\right)$.

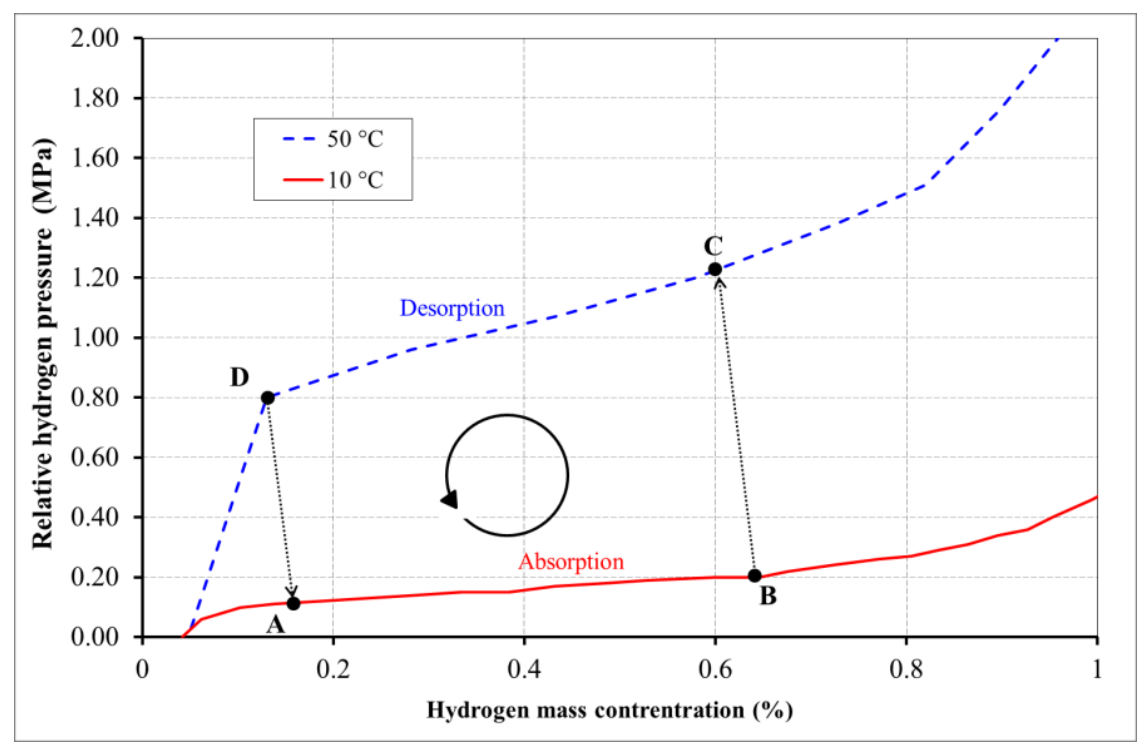

Fig. 1. Description of the temperature cycle of hydrogen compression using the $\mathrm{La}_{14} \mathrm{Ce}_{2} \mathrm{Ni} 84$ alloy.

As a result of supplying the heat between points $\mathrm{BC}$, the temperature increases in $40{ }^{\circ} \mathrm{C}$, which is reflected in the pressure increase approximately up to $1.22 \mathrm{MPa}$. Due to the desorption effect accompanied with the pressure increase, hydrogen is released in a small amount and increases the pressure of gaseous hydrogen between the alloy grains; as a result, the shift of point $\mathrm{C}$ to the area with a lower concentration significantly depends on the grain size and on the volume of the free space between the alloy grains.

After the pressure is increased by heating the alloy, it is possible to start hydrogen desorption between points $\mathrm{C}$ and $\mathrm{D}$ that is accompanied with the consumption of the supplied reaction heat. Concentration decrease is only possible after achieving the value of $0.13 \%$, as at lower concentrations the pressure decreases very quickly. The pressure in point $\mathrm{D}$ reaches the value of $0.8 \mathrm{MPa}$; therefore, the compression ratio at hydrogen compression by the temperature cycle can be identified while using the formula

$$
\varepsilon_{\mathrm{k}}=\frac{p_{\mathrm{D}}}{p_{\mathrm{B}}}
$$


whereas $p_{\mathrm{D}}$ is hydrogen pressure in point $\mathrm{D}(\mathrm{Pa}), p_{\mathrm{B}}-$ hydrogen pressure in point $\mathrm{B}(\mathrm{Pa})$. During the operation of a cyclical compressor with the used $\mathrm{La}_{0.85} \mathrm{Ce}_{0.15} \mathrm{Ni}_{5}$ alloy within the temperature range from 10 to $50{ }^{\circ} \mathrm{C}$ and the mass concentrations of 0.16 and $0.66 \%$, the compression ratio resulting from measurements of PCI curves is $\varepsilon_{\mathrm{k}}=4$.

To achieve the temperature and pressure of the baseline point A again, the storage tank must be cooled and the heat must be removed

$$
Q_{\mathrm{DA}}=-\left[\sum_{i}\left(m_{i} \cdot c_{i}\right) \cdot \Delta T+q_{\mathrm{abs}} \cdot \Delta V_{\mathrm{abs}}{ }_{2}\right]
$$

whereas $q_{\text {abs }}$ - reaction heat at hydrogen absorption $\left(\mathrm{J} \cdot \mathrm{m}^{-3}\right), \Delta V_{\text {abs } \mathrm{H} 2}$ - amount of absorbed hydrogen at temperature decrease in $\Delta T\left(\mathrm{~m}^{3}\right)$. On the basis of the cycle, the basic concept of the compressor described in the next chapter was proposed.

\section{Experimental measurements}

Operation of a heat pump used in a hydrogen compressor significantly differs from the conventional heat pump use in heating. The difference consists mainly in jump changes in temperatures of liquids supplied into the condenser and evaporator when switching between the heating and the cooling modes. At the Department of Energy Technology in Košice there is a currently running development of a prototype of a hydrogen compressor using MH materials within the APVV project. For this purpose, a water-to-water heat pump with the heating power of $1.5 \mathrm{~kW}$ and the cooling power of $1.2 \mathrm{~kW}$ is being developed in cooperation with the TATRAMAT, s.r.o. company. R134a (weight of $700 \mathrm{~g}$ ) is used as the coolant. The compressor has a standard operating input power of $400 \mathrm{~W}$. The cooling power is optimised for a two-stage tandem compressor. During the measurement, the heat pump was connected as shown in the scheme in Figure 2.

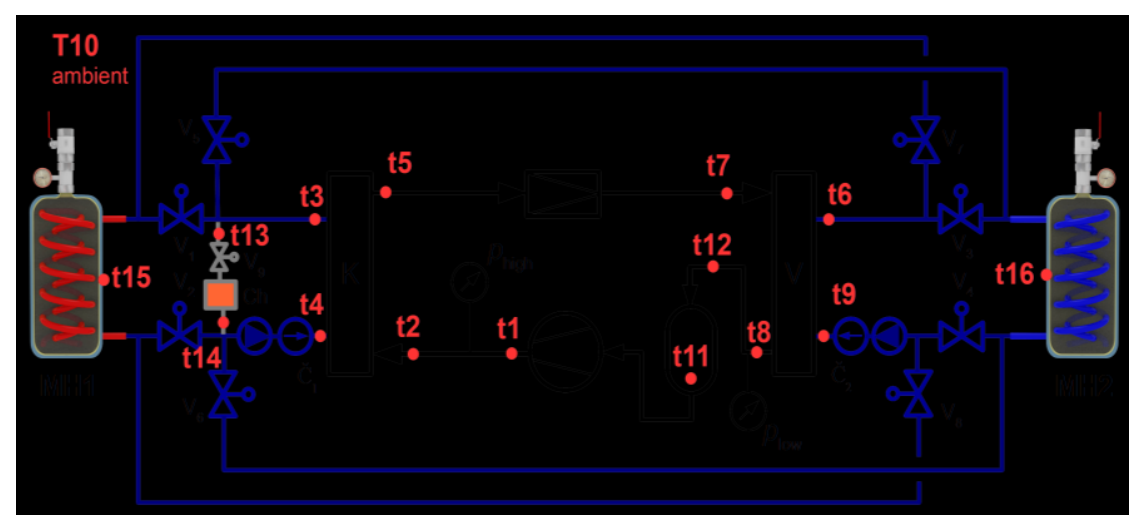

Fig. 2. Connection scheme of the hydrogen compressor using MH tanks with a heat pump.

The measurements were carried out using MH tanks of HBond 500 type with the $\mathrm{La}_{0.85} \mathrm{Ce}_{0.15} \mathrm{Ni}_{5}$ alloy weighing $3.125 \mathrm{~kg}$ in a single tank.

Once the $V_{1}$ to $V_{4}$ valves are opened, water from the condenser flows into the left MH1 tank and water from the evaporator flows into the right $\mathrm{MH} 2$ tank. Once the $\mathrm{V}_{1}$ to $\mathrm{V}_{4}$ valves are closed and the $\mathrm{V}_{5}$ to $\mathrm{V}_{8}$ valves are opened, there is a switch between the cooling mode and the heating mode. Such switch invokes supplying the cold water into the condenser and hot water into the evaporator. The purpose of the measurements is thus provide a closer view of thermodynamic changes occurring when individual tanks are switched from the heating mode to the cooling mode (and vice versa) between the tank temperatures of 10 and $50^{\circ} \mathrm{C}$ (Fig. 3). 
Temperatures were scanned using electronic 1-wire sensors of the DS18B20 type with the measurement range from -55 to $125{ }^{\circ} \mathrm{C}$. The temperature measurement accuracy is $\pm 0.5^{\circ} \mathrm{C}$. The pressure was scanned using Huba Control sensors with the range from $3 \mathrm{MPa}$ (pressure behind the compressor) to $1.6 \mathrm{MPa}$ (pressure behind the evaporator). The maximum measurement accuracy is $0.5 \%$ of the sensor's range. The output current signal from pressure sensors is 4 to $20 \mathrm{~mA}$, conversed by a resistor into the voltage signal. The values were recorded using the Raspberry Pi PC with additional cards for 1-wire sensors and the A/D converter.

As for heat pumps, the thermal power removed from the condenser is always higher than the cooling power received by the evaporator. Therefore, an additional air cooler is placed on the condenser's side.

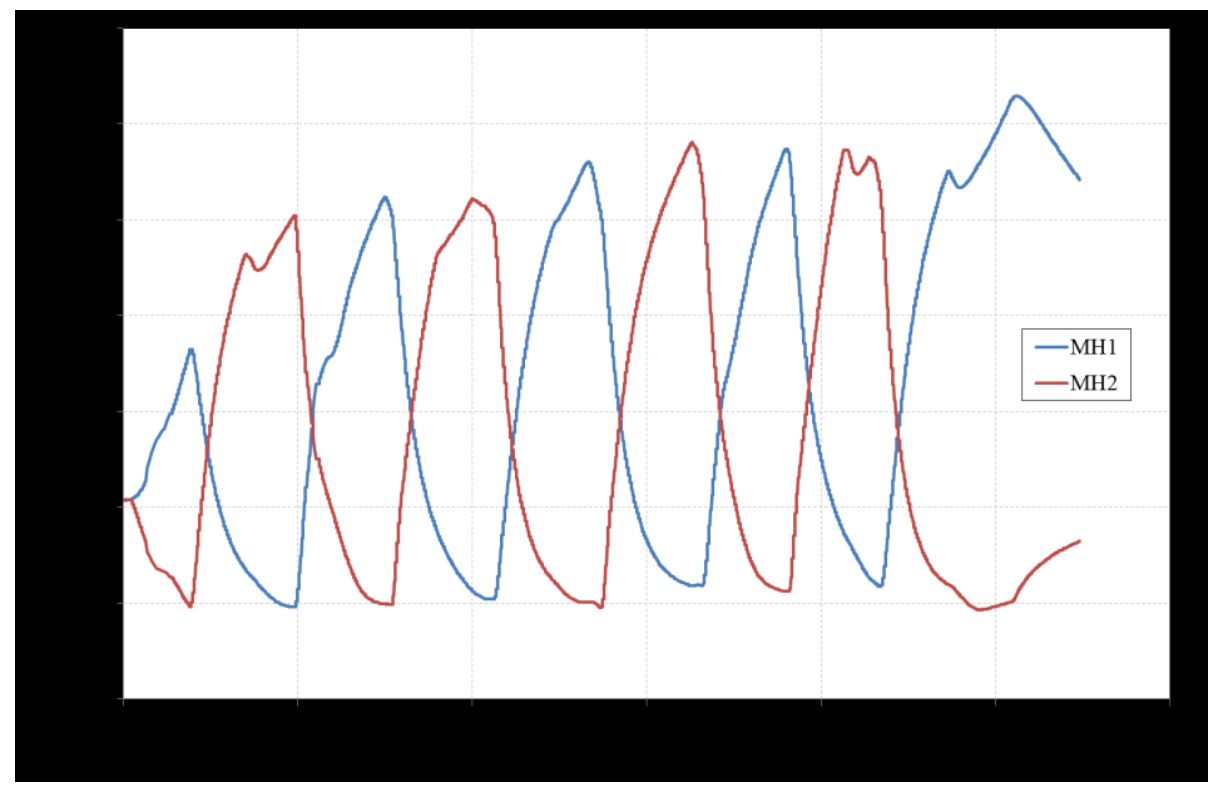

Fig. 3. Curves of surface temperatures of MH tanks during eight switches between the heating mode and the cooling mode.

The curve of coolant pressures before and behind the compressor, including the measured active electric input into the compressor is presented in Figure 4. The vertical dash line represents the time of switching from the cooling mode to the heating mode. With regard to the fact that warmer water is supplied in jumps into the evaporator, such switch is followed by a gradual increase in the coolant temperature before the compressor, leading also to the consequent increase in the relative pressure behind the compressor. The value of active electric input into the compressor is increased as well, decreasing thus the COP of the heat pump.

When the heat pump operation is not interfered with, emergency stop of the device frequently occurs due to exceeding the maximum permissible pressure behind the compressor which is detected by a safety pressure switch with the preset stop pressure of 2.3 $\mathrm{MPa}$. To prevent such heat pump stoppage and achieve a continuous operation of the device, an air cooler $(\mathrm{Ch})$ was turned on before switching between the heating and the cooling of $\mathrm{MH}$ tanks. 


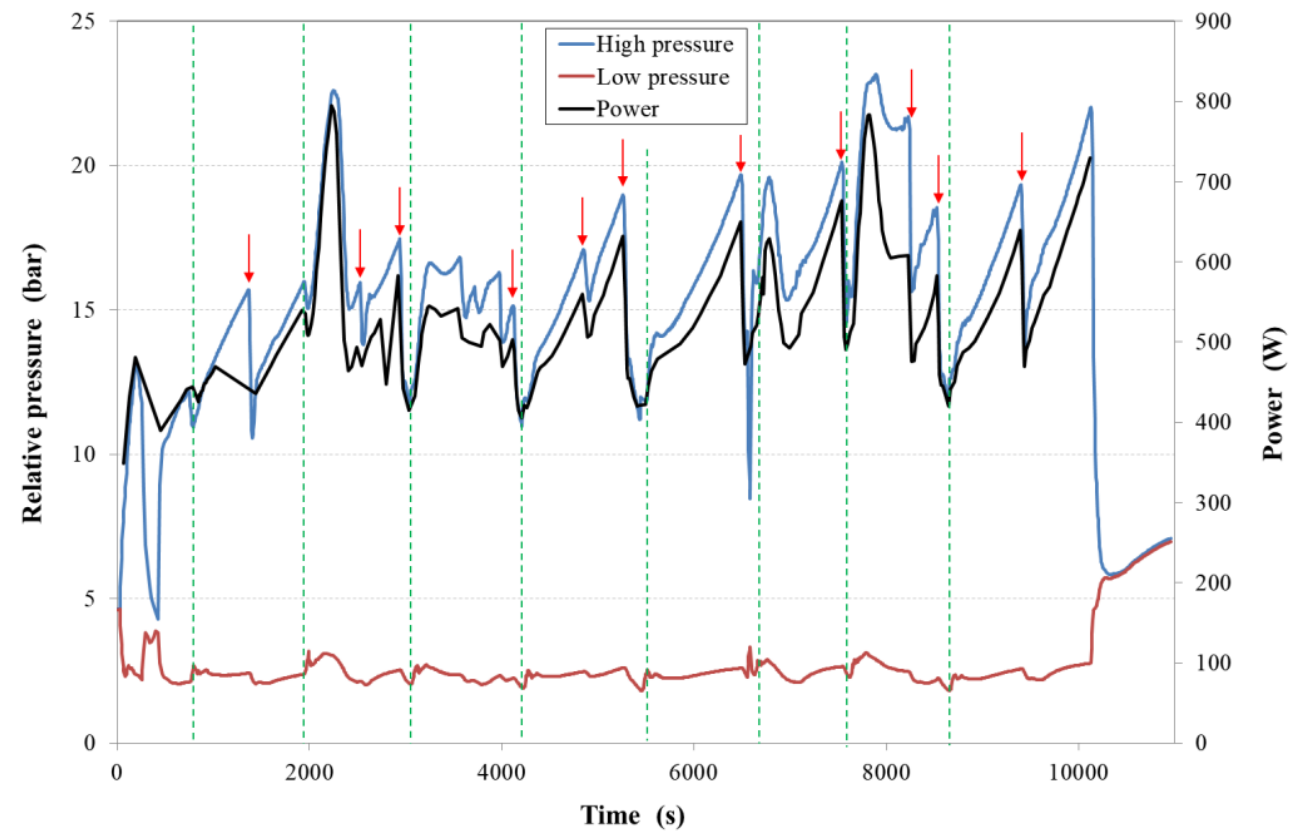

Fig. 4. Curves of coolant pressure before and behind the compressor, including the measured active electric input into the compressor.

MH1 and MH2 tanks contain tubular spiral heat exchangers with a rather small internal diameter of pipes; this significantly decreases the water flow rate and facilitates low COP values during the hydrogen compressor operation. This drawback can be significantly eliminated by creating a second-stage of the compressor, i.e. adding another tandem pair of $\mathrm{MH}$ tanks to the first stage.

\section{Conclusion}

The present article deals with the possibility of using a heat pump in the construction of a hydrogen compressor using the heat cycle at hydrogen absorption and desorption into metal hydrides. We carried out the measurement with cyclical switching between the heating and cooling of $\mathrm{MH}$ tanks, while maintaining a continuous operation of the heat pump in the event that before the switch the water in the condenser was cooled below $45^{\circ} \mathrm{C}$, which decreased the subsequent heating up of the evaporator. By measuring the operating parameters and subsequent adjustment of the compressor operation, a stable and continuous heat pump operation may be achieved. Also, the minimum time for changing the tank temperature between the temperatures of 10 and $50{ }^{\circ} \mathrm{C}$ was determined as $700 \mathrm{~s}$ in the existing conditions. The compressor operated as described above must also be subjected to energy optimisation because the average COP is approximately 1, whereas in a simulated run of heating and cooling of tanks with water the average COP was 3.3. The solution consists in concurrent addition of the second stage of the hydrogen compressor, using one more tandem pair of $\mathrm{MH}$ tanks containing the alloy with the composition corresponding to the required pressure behind the second stage of the compressor. 
This paper was written with the financial support of the granting agency APPV within the project solution No. APVV-15-0202, of the granting agency VEGA within the project solution No. 1/0752/16 and of the granting agency KEGA within the project solution No. 005TUKE-4/2016.

\section{References}

1. A. Sarkar, R. Benerjee, International journal of hydrogen energy 30, 8 (2005)

2. S. Bouaricha, J. Huot, D. Guay, R. Schulz, Hydrogen Energy 27, 9 (2002)

3. W. Grochala, P. Edwards, Chem Rev 104 (2004)

4. H. Imamura, K. Masanrik, M. Kosuhara, H. Katsumoto et. all, J Alloys Compds 381,1-2 (2005)

5. A. Kapjor, T. Gressak, J. Huzvar, AIP Conference Proceedings (2014)

6. M. Vantuch, J. Huzvar, A. Kapjor, EPJ Web of Conferences 67 (2014)

7. G. Popeneciu, V. Almasan, I. Coldea, D. Lupu et all, Journal of Physics 182, (2009)

8. P. Mlynár, M. Masaryk, BME Budapest (2012)

9. K. Ferstl, M. Masaryk, Prenos tepla (Heat transfer) (2011)

10. M. V. Lototskyy, V. A. Yartys, B. G. Bollet, Boweman R. C, International journal of hydrogen energy 39, 11(2014)

11. N. Jasminská, T. Brestovič, L. Bednárová, M. Lázár, R. Dobáková, International Journal of Engineering Research and Science 3, 9 (2017)

12. L. Bednárová, N. Jasminská, T. Brestovič, M. Lázár, R. Dobáková, International Research Journal of Advanced Engineering and Science 2, 4 (2017) 